\title{
Intersections between Human Trafficking and Education: Toward New Research Agendas
}

\author{
Bob Spires \\ University of Richmond \\ bspires@richmond.edu
}

\begin{abstract}
Human trafficking is a social issue that has gained attention in the media and in scholarship. A growing number of anti-trafficking organizations and actors have begun to use education to diverse ends. Although not often associated with human trafficking, education is a common tool used by anti-trafficking organizations, whether as a prevention tool to reduce the vulnerability of people at-risk of trafficking, or as a service to trafficking survivors to improve their lives. Lack of access to education, or to quality education, is also a factor in exposure to human trafficking, whether that be in terms of debt bondage, domestic servitude, forced labor, child marriage or other issues related to human trafficking. More explicit connections need to be made between the work being done in anti-trafficking spheres and the scholarship of education in order to better understand how to improve the quality and effectiveness of education-related efforts. This essay explores the connections between human trafficking and education, including: intersections between the two fields, definitional issues, ways in which education is used in anti-trafficking efforts, and policy implications.
\end{abstract}

\section{Intersections Between Human Trafficking and Education}

Human trafficking has profound and pronounced connections to the education sector and to education broadly defined despite the seemingly disparate nature of the two topics at first glance. Understanding how education is used as a prevention tool, how education is conceptualized for vulnerable groups, and how education is provided as a service for survivors and at-risk populations are important issues but little discussion of these issues occurs in the formal scholarly literature, and even less empirical work is done on the effectiveness and impacts of education in anti-trafficking work. Of additional importance are the broad socio-economic issues that connect human trafficking and education, as well as the growing efforts to use education as awareness raising for the public. Scholarly discourse of human trafficking, anti-trafficking Nongovernmental organizations (NGOs) and government agencies tasked with addressing human trafficking rarely crosses over into education discourse. More theoretical and empirical scholarship is needed to link education work on topics such as effective teaching and learning, and the implementation of educational services by anti-trafficking actors, and policy makers. Whether it is seen as a prevention tool, a public awareness tool or a service for survivors, 
education is often viewed as an important component of anti-trafficking work by a variety of stakeholders (Laser-Maira, Huey, Castro, Ehrlich \& Nicotera, 2018; OVCTTAC, n.d.a; UNODC, n.d.). However, there is little interaction between the work occurring in the anti-trafficking movement, and the formal discipline of education, despite the many overlapping elements, and the disconnection is likely due to a general lack of understanding of the various connections between the two spheres. This essay examines the broad educational issues in relation to human trafficking, including those educational issues impacting vulnerability to trafficking by specific demographic groups. Next, the various ways in which education is used in anti-trafficking work for specific human trafficking related purposes are explored. Finally, policy implications of the intersections between education and human trafficking are discussed. This essay draws out the ways in which human trafficking intersects with education in order to point toward areas for further inquiry.

\section{Defining Human Trafficking and Education}

In order to better understand the complexities of the central topics of this essay, the following sections will outline the definitions and controversies surrounding the respective definitions below.

\section{Human trafficking}

Although general world-wide agreement among national governments on the definition of human trafficking exists, issues remain regarding the interpretation of the definition at the local, regional, national and international levels. The generally accepted definition comes from the United Nation's (UN OHCHR, 2000) policy, typically referred to as the Palermo Protocol, which established that human trafficking is the "recruitment, transportation, transfer, harbouring or receipt of persons" through force, threat or coercion, "for the purpose of exploitation" (Article 3a). Despite the establishment of this policy, and its associated expectations of national signatories to address the issue in their countries through prevention, protection and prosecution efforts, local subjective interpretational issues, as well as implementation issues remain and inconsistency persists. One widely-noted challenge frustrating effective anti-trafficking efforts comes from the inconsistency in data and research on trafficking, particularly regarding the size, scope and scale of the issue (Feingold, 2017; Gozdziak \& Bump, 2008). Despite large-scale efforts, such as the Global Slavery Index (n.d.), to collect and analyze larger-scale data on trafficking, these approaches are not without criticism (Gallagher, 2017). Finally, the Palermo Protocol is not without its critics, particularly in accusing the United States (who's annual Trafficking in Persons report ranks countries based on anti-trafficking efforts) of inconsistently ranking countries based on unclear methodologies and political bias (Harmon, Arnon, \& Park, 2020; Murray, 2020). Therefore, definitional issues are likely to remain in the field and continue to cause challenges for researchers and practitioners.

\section{Limited Research on the Impact of Education as Prevention}

Education is challenging to define and to measure, particularly in terms of anti-trafficking approaches. Dewey (1934) noted that education should provide "the young the things they need in order to develop in an orderly, sequential way into members of society." Smith (2021) defines education as "the wise, hopeful and respectful cultivation of learning and change undertaken in the belief that we all should have the chance to share in life." King (1947) argued, "Intelligence plus 
character - that is the goal of true education". Foshey (1991) stated that education should provide "...as full a realization as possible of what it is to be a human being." Freire (1972) argued for a more liberating approach which he called critical education, which centered around problemposing, critical analysis of oppressive social structures, and a privileging of dialogue and anti-hierarchical approaches to schools and student/teacher relationships.

For our purposes, the author defines education in the broadest possible terms, incorporating all above conceptualizations of education, a necessity which will be born out below as a variety of usages and purposes of education will be shown to intersect with human trafficking. Education, in this sense, includes (but is not limited to) formal and informal education, state and national curriculum as well as NGO-developed instructional materials, local community awareness raising efforts and international media campaigns, training of vulnerable groups, law enforcement, healthcare workers, legal practitioners, NGO staff, policy makers and others. The diversity of ways education intersects with human trafficking illustrates the challenge with evaluating the effects of various approaches, as well as connecting the broader educational issues, such as formal educational attainment of marginalized groups, and points to the challenge of developing comprehensive research agendas on the confluence of anti-trafficking and education efforts.

Connections between education and human trafficking are under-researched and under-theorized despite education's wide use as an anti-trafficking strategy by many actors. From national guidelines for incorporating human trafficking prevention components in school curriculum (US Department of Education, 2017; US Department of Health and Human Services, 2020) to the widespread use of education as a prevention tool by NGOs (A21, 2021), intersections remain prevalent but the effectiveness of these programs and approaches is poorly understood. Despite this lack of comprehensive analysis on the intersections, this essay attempts to pull out some of the key areas that need further examination as well as outlines topics in need of exploration.

\section{Complex Connections between Education and Socioeconomic Issues}

Socio-economic issues (e.g. local, regional, national and global economic dynamics, statelessness, undocumented/informal migration, minority group membership) are the biggest predictors of educational outcomes (Behrman, 1996; Rose, 2007), as well as human trafficking vulnerability or susceptibility (Bales, 2007; Laczko \& Gozdziak, 2005). Severely impoverished people across the globe are less likely to access quality education, attain educational credentials and matriculate to higher levels of education (Murdock, Zey, Cline, \& Klineberg, 2010). Socially and economically disadvantaged groups are more likely to be: precarious workers in volatile labor sectors, willing to take risky jobs and travel informally, discriminated against due to classism or racism in the workplace, in poorer health, and exposed to hazardous working conditions. In addition, disadvantaged groups have fewer resources to commit to recourse for exploitative practices, and less access to avenues of restorative justice, particularly when migrating informally and beyond their local communities.

Extremely impoverished families may be more likely to have children and youth who must also contribute to the family's survival through work. Contrary to sensationalized reports exaggerating the prevalence of parents selling their children to traffickers (Keely, 2020; Raphael, 
2020), these instances are not the norm (Banks \& Kyckelhahn, 2011), often as responses to moral panic (Bernstein, 2018; Gozdzkiak, 2016). More often, parents, as well as the children and youth themselves, weigh the potential risks between difficult choices in which neither option (working or not working) is particularly positive, and survival for themselves and their family is of utmost priority. Child laborers then face compounded vulnerabilities (US Department of Labor, n.d.), particularly when migrating informally to contexts where child labor is restricted (Huijsmans \& Baker, 2012), or when belonging to vulnerable or marginalized groups (UNODC, 2008).

Armed conflicts further exacerbate human trafficking and extreme exploitation. Fleeing refugees are often either forcibly trafficked by armed groups like Boko Haram (Ferguson, 2020), intercepted during border crossings and migration processes, or even exploited in refugee camps in various ways. Vulnerability of specific targeted groups, for instance religious minorities like the Rohingya in Burma (UN News, 2017), is heightened during armed conflict, pushing these groups into more precarious situations, which include informal migration, lack of access to education, language and cultural barriers in host communities. One prominent example in Africa is the high-profile case of Lord's Resistance Army (LRA) led by Joseph Kony, who trafficked women as sex slaves for his soldiers, and children as child soldiers in Central Africa (Campbell, 2017). Although LRA has largely been reduced to a fringe rebel group in comparison to a decade or more ago, Kony left a generation of uneducated and traumatized youth in his wake, further disrupting long term development of rural areas most affected by the conflicts.

In addition to armed conflict and poverty, human trafficking is also interconnected with many other socio-economic and country specific political issues including migration, immigration and corruption (Bales, 2004; 2005; 2007). Consequently, these socio-economic issues also highly impact educational outcomes. Socio-economic status is considered one of the most important outside-the-school factors impacting academic success of students (Aikens \& Barbarin, 2008; Morgan, Farkas, Hillemeier, \& Maczuga, 2009). Intra-country migrant children often have incomplete and disrupted educational experiences due to the transience of their family work situations. It is common in the US for migrant children to attend multiple schools in various states each year, and when language barrier is added to the host of issues they face, these students often do not receive the educational services and support that they need. Inter-country migration adds an additional barrier to educational attainment, with added delays in accessing local schools due to: mismatches between educational systems and curriculum across countries, language barriers, lack of understanding available social services and other resources, fear of government officials and law enforcement, lack of resources such as school supplies, disruptive and stressful home environments, and social isolation. These and other issues compound to reduce educational effectiveness, which in turn, increases vulnerability to exploitation and trafficking, as well as long-term marginalization. Holistic understanding of the complex relationships between human trafficking, education and socio-economic/political issues is needed, particularly through more comprehensive and nuanced qualitative as well as quantitative research that accounts for the complicated interconnections.

Language is a particularly important educational issue related to trafficking survivors and often a barrier to full participation in the society in which they experienced exploitation (OVCTTAC, n.d.a). For instance, in Thailand where significant numbers of hill tribe people as well as 
migrants from other Southeast Asian countries are living, Thai language is likely not spoken fluently by these groups and therefore educational achievement is further limited (Spires, 2014; 2015). In the United States where large numbers of informal migrants speak Spanish, or indigenous Latin American languages, many communities are resistant to English as a second language or native language service provision in the school setting, further increasing informal migrant vulnerability. Most trafficking survivors in the UK are from non-English speaking countries and without English skills, they struggle to integrate into British society (Darby, 2019). In the contemporary workplace as well as in academic educational settings, literacy is a crucial foundational academic tool to access higher levels of education. Thus, effective education for human trafficking prevention and social mobility must emphasize literacy.

\section{How Education is Used in Anti-Trafficking Work}

\section{Education as prevention}

Informing vulnerable groups, such as informal migrants and ethnic minorities, is one of the most important goals of human trafficking awareness raising through education (Ellery, 2019). In addition, awareness raising campaigns targeting the general public have also been used in formal schools across the world (A21, n.d.; Tidball \& Rajaram, 2017). Although trafficking awareness raising campaigns have been criticized for their lack of effectiveness, they continue to proliferate (Haynes, 2019). Governmental actors and NGOs provide human trafficking prevention educational materials at informal border crossings, immigration centers and work sites (UN OHCHR, n.d.). The effectiveness of these efforts is unclear, as the migrants may have already made the decision to migrate informally and are already at high risk of trafficking or even in the process of being trafficked through a labor broker. Other methods of education as prevention include educational programs at sending communities where migrants' decision-making can be better informed. In addition to the dangers involved in informal migration, vulnerable groups also need comprehensive education on their rights as laborers, both internationally and within their home countries. Informal migrants may be unaware of their rights including their ability to contact law enforcement and government officials if exploited. Further, many education as prevention efforts posit that these migrants may not fully comprehend safe migration tactics that can reduce vulnerability to trafficking. At-risk groups are, however, often quite informed of the risks of migration and trafficking, and are often basing decision making between difficult life choices, none of which are advantageous due to their economic and social situations (Spires \& Tost, 2017; Tost, Spires, \& In, 2020).

As important as informing at-risk groups on risks is to provide education that reduces risks in terms of providing training, academic education, credentials and skills to improve their standard of living. The provision of formal and non-formal education has long-term impact on risk reduction (Bales, 2007; Ezeibe, Oguonu, Ajaero, Osadebe, Agbo, \& Uwaechia, 2021). Risk to human trafficking is most highly impacted by the economically and socially precarious circumstances, and thus, these vulnerabilities are reduced through improvement of social mobility (Barner, Okech \& Camp, 2014). Education certainly can improve social mobility, but education is most effective when sensitive to local community needs and cultural understandings rather than one-size-fits-all approaches. NGOs may be flexible and nimble enough to adjust to local needs and conditions, but also must comply with local education regulations in the countries where they provide educational services. 
Another complex element within the education as prevention sphere is the topic of child labor. Child labor is viewed differently across countries and cultures. Children in rural areas are often crucial economic contributors to families and marginalized families often rely even more heavily on children as contributors. Child laborers become increasingly susceptible to human trafficking as they work further from their homes and communities or in more precarious work situations. With current trends of urbanization and ecological crisis, vulnerable families may consider sending their children afar as wage earners and thus increase their vulnerability. Without access to education as well as family resources that allow for children to attend educational programs, child laborers are often destined to long-term manual or unskilled jobs for little pay and they face workplace exploitation and mistreatment. Expanding education must account for the economic situations of their families that create circumstances where parents feel pressure to send their children to work. Without education that addresses comprehensive economic realities of families, high levels of child laborers who are trafficked will remain a significant phenomenon in distressed communities and with economically disadvantaged groups.

\section{Formal education as a service for survivors}

Formal education in the form of accredited and accepted educational institutions providing recognized educational credentials is crucial for human trafficking survivors (Ellery, 2019). In all contemporary societies, educational credentials offer the holder access to better opportunities and open occupational doors not available to low-skilled workers. Without the accepted credentials, already vulnerable groups will likely remain marginalized, and real social mobility is unlikely. In terms of reducing exposure to exploitation via human trafficking in the long-term for survivors, provision of access to recognized educational credentials is essential. Although formal education may include academic schooling oriented toward tertiary education, it may also include vocational and technical training, with the central focus on gaining certifications, diploma or degrees widely accepted in the society and the workplace. Unfortunately, for marginalized groups, vulnerable individuals, and particularly trafficking survivors, long gaps in their education often cause issues with reintegrating into the formal education system (Surtees, 2013). Further, NGOs have become key deliverers of education in some countries due to weak infrastructure in formal education ministries, departments or systems (Creative Associates International, 2002). Acceptance of informal or undocumented migrants into schools also varies by country and even within country, with local community pressure coming to bear on school officials' willingness to allow these students access. Trafficking survivors often require additional services such as trauma-informed approaches, special needs services, language services, medical services, nutrition and other elements that require substantial school resources and professional knowledge (Surtees, 2013).

\section{Education and child labor}

According to Boyden (1994), education and child labor are intimately connected. Provision of education can reduce full-time work among children, but has little effect on reducing part-time work among children, and education is often one of the causes of child labor, as impoverished families depend on income from the child laborer to pay for educational costs. Greater resources are needed world-wide by governments to strengthen primary education provision and reduce or eliminate schooling costs for families. According to the International Labor Organization (ILO, n.d.a), universal education provision, alongside improved social protections and strengthening of 
the rights of the child have significant impacts on reducing child labor. Further, the ILO (n.d.b) argues that universal primary education must be linked to effective secondary and tertiary education that matches the needs of the marketplace in both formal and informal employment, in order for children who work to gain long-term benefits from leaving the labor market for school. UNICEF (Guarcello, Lyon, \& Valdivia, 2015) found that children's employment was falling and school attendance was rising among 19 developing countries. However, some of these countries saw increases in children combining schooling and employment, as well as increasing time commitments to work for working children, particularly the least developed regions of Latin America, Africa and Asia. Additionally in these countries, a large proportion of child laborers who are not attending schooling are doing unpaid family work. School attendance for children combining schooling and work is much lower than their peers who are not working, and these children fall behind their peers regarding academic performance and grade matriculation. International efforts such as the ILO's C138 Minimum Age Convention (ILO, 1973) to establish world-wide standards for child employment emphasize the global acknowledgement of the connection between child labor and other forms of exploitation but more large-scale efforts are needed to bridge the gap between policy and practice related to child laborers and the provision of education (Kluttz, 2015). Each of these findings emphasize the importance of addressing child labor through education as a preventative tool to reduce vulnerability to trafficking.

World-wide we continue to see a tension between the human rights-based approach to education which focuses on the provision of education to all children, and the right to survival through work for school-age children. The growing economic inequality we see globally has driven more impoverished children into precarious work (UN DESA, 2020) and the norm of contemporary global neoliberal capitalists is that major economic actors depend on large numbers of desperate, informal and precarious workers (Betti, 2016; Breman \& Van der Linden, 2014; Standing, 2009), and many powerful actors actively work to destabilize the lives of precarious workers in the neoliberal age (Klein, 2008). The interests of global capitalism and the need for disadvantaged children to access both education and simultaneously survive are at odds. The inherent contradictions between the United Nations 2030 Sustainable Development Goals (UN DESA, 2015) and the interests of global multinational corporations are apparent and if we are to reach these goals, we must acknowledge the paradox between sustainability and neoliberal profiteering.

\section{Non-formal education}

Non-formal education, in the form of practical, work-oriented skills and knowledge provided outside the formal educational institutions, can also be effective at reducing human trafficking vulnerability and improving social mobility for survivors as well as at-risk groups broadly defined. For instance, in villages across the globe, high formal academic skills may not actually match the local job market and thus, more practical skills may be more situationally appropriate to effectively improve their economic situation. General skills such as operating a small business, general money skills and basic literacy are applicable to a variety of occupations and may be more community appropriate than academic training aimed at tertiary education preparation. However, empirical work on general education programs for trafficking victims have found that programs are often underfunded and effectiveness is often difficult to verify (Ogonor, \& Osunde, 2007), particularly without individualized case management and other targeted services for survivors (Gozdziak \& Lowell, 2016). 
Vocational training on specific technical skills are important, particularly when the target group has aged out of the formal education system or individuals are not particularly interested or adept at formal academic study. For these reasons, many anti-trafficking organizations use vocational education as a tool to support survivors (Nagaraj, 2018). Local community dynamics must be taken into account, along with larger-scale vocational needs in the marketplace, if these vocational education programs are to be successful. Education providers focusing on vocational training through non-formal education must take a comprehensive approach to understanding the job market, local needs and culture as well as long-term trends in the workplace (Spires, 2014; 2015).

Credentialing is a crucial issue for non-formal education. Whether non-formal or formal approaches are being implemented for human trafficking survivors and at-risk groups, credentials for educational program completion must be widely accepted. In other words, if an NGO is providing training in welding, they must ensure that the welding credential that they provide to their students is accepted in the workplace and that the welding program completers can be gainfully employed in welding positions after their programs. Too often, NGOs in antitrafficking do not verify the match to differing industry standards in varied contexts (CITE).

Another major issue facing non-formal education-providing NGOs is the lack of training of teachers. Although many educators employed by NGO-based education programs are often more passionate and dedicated to their students' success due to their attraction to work with disadvantaged groups, they often lack formal training in lesson planning, innovative teaching techniques, engaging classroom activities and strategies that are known to improve motivation and retention of knowledge (Chall, 2002). NGOs often face a lack of funding to pay certified teachers appropriate wages and thus resort to hiring teachers based on interest and willingness, rather than credentials and training. The gap between non-formal educators' training and the preparation of teachers in formal educational settings often means that students in NGO-based educational settings do not receive rigorous, consistent and effective learning opportunities. Inconsistency is exacerbated with the reliance on voluntourism by NGOs (Falvey, 2014), which may include short-term language instruction that lacks follow-through and alignment to the real needs, abilities and learning levels of the students (Jakubiak, 2016).

\section{Voluntourism and education}

Education through NGOs has increasingly faced scrutiny in recent years (Friedus, 2017; Jakubiak, 2016; Loh, 2019). Volunteer tourism or voluntourism has grown in popularity, where travellers volunteer for an organization or community as part of their travel experience. Education is a popular sector in which volunteers often work for NGOs, and the quality of education provided by often untrained teachers, as well as the real impact of this volunteer work on the lives of trafficking survivors and at-risk groups and in host communities is often unclear and can vary greatly (Dennis, 2020; Hechenberger, 2019). Further, education provided to human trafficking survivors by NGOs staffed by white western voluntourists has been criticized as being an example of the "white savior complex" and seen as benefiting the volunteers more than the recipients of the education or other services (Cortes, 2018), sometimes to tragic ends (Dennis, 2020; No White Saviors, 2018). Although NGOs have some advantages in their ability to be nimble, individualized and flexible in their work, these advantages do not outweigh the 
importance of quality education, and the effectiveness of teachers, whether in formal or nonformal settings. Thus, in order for education to be an effective service for survivors, providers must prioritize quality in terms of teacher experience and expertise, curriculum, acceptability of credentials, local needs, and match to survivors' interests and skills.

\section{Awareness raising and informing the public about human trafficking}

Significant resources and attention in the anti-trafficking arena are dedicated to awareness raising campaigns across the globe, to varying degrees of success. The general public, although changing in recent years, is typically unfamiliar with the complex dynamics and contextual factors related to human trafficking. Therefore, it is crucial to educate the public to recognize modern slavery, human trafficking, forced labour, child labour and other forms of human exploitation in their own communities. However, as with other arenas related to human trafficking, varying interests also inject their influence, bias and secondary purposes into these campaigns. For instance, faith-based organizations may sensationalize the issue, framing human trafficking in moral, ethical or religious terms, while organizations with ties to the business community, may frame trafficking in strictly economic terms.

Across the globe, many awareness raising campaigns have been implemented in a variety of settings, including in middle and high schools in the US (Littrell, 2015), in airports across the globe (Department of Homeland Security, n.d.), and in public spaces such as public transportation hubs and tourist spots. Law enforcement are central players in both public awareness raising, recognition of exploitation, and action to address real issues in communities. Worldwide, particularly since the Palermo Protocol, most nation-states have worked to improve law enforcement training on the issue, and policy that enables more effective law enforcement, and legal tools to protect survivors and arrest perpetrators, as well as partnerships with other governmental and nongovernmental organizations within communities. However, discrepancies remain in the law enforcement sector in both understanding of the issue and most effective approaches to addressing the issue if and when they encounter trafficking. Further, effective prosecution of perpetrators requires comprehensive collaboration between law enforcement, the legal community, and the judicial system as a whole. Effective legal frameworks also involve education for the legal community, including comprehensive training for attorneys, judges and other professionals, in particular to avoid misidentification of human trafficking victims, the development of legal frameworks and policy tools to assist in prosecution of perpetrators, and provision of legal avenues for the appropriate support of survivors.

\section{Policy Implications}

In order for lawmakers and the legal community to develop effective legal tools to address trafficking, these actors too must be educated comprehensively on the complex issues surrounding trafficking. Effective policy must take a nuanced approach, informed by the specific challenges faced by survivors (e.g. survivor video testimony, financial support while living in shelters, risk to extended family caused by testimony), informed by the specific local, regional and national contexts, and that allows for flexibility that favors survivor choice. However, support and implementation of education and other aftercare services for survivors across various settings, countries and contexts remains inconsistent, susceptible to political and economic 
trends, and vulnerable to corruption (Dell et al., 2019). Further, discrepancies between urban and rural community implementation, even within a single country context, can vary wildly.

Collaboration between the legal community and direct services, while uneven across the globe, is absolutely essential to effectively addressing human trafficking. Survivors of human trafficking have been misidentified by law enforcement far too often, and effective integration between community services, law enforcement and the legal community is needed to reduce the likelihood of re-victimization of survivors. Further, local contexts are often better understood by local organizations, such as grassroots NGOs and community agencies. Law enforcement should also be educated on direct services organizations beyond their community, particularly in rural areas, where less comprehensive services are available, to ensure that survivors are correctly served, and services (e.g. psychological and physical care, job training, transition services, legal support) are case specific and tailored to survivors' needs and community-oriented.

\section{Conclusion}

Contrary to the initial sense that they are separate spheres, human trafficking and education intersect in quite powerful and diverse ways. Although education is often a go-to strategy for anti-trafficking organizations as well as other entities doing anti-trafficking work, the ways in which education is employed varies greatly in quality, impact, resources, purpose, and stakeholder group. Further, much like other uses of education across society, it can be influenced by (and influence) politics, economics, local context, and the biases and interests of the various actors involved. More work is needed to understand which uses of education in anti-trafficking efforts are most effective, as well as which uses are less effective, or even counter-productive. This essay set forth an overview of the various ways in which education intersects with human trafficking, how education is used in anti-trafficking work, and some of the criticisms of the ways in which education is used in the anti-trafficking efforts world-wide. Now what is needed is more empirical work to establish effective practices as well as identify the ineffective practices to be avoided in the use of education in anti-trafficking work. 


\section{References}

A21. (2021). Education is essential to end human trafficking. Retrieved from https://www.a21.org/content/education/grc2u8

A21. (n.d.). Bodies are not commodities: A high school curriculum. Retrieved from https://www.a21.org/content/education/grc2u8

Aikens, N. L., \& Barbarin, O. (2008). Socioeconomic differences in reading trajectories: The contribution of family, neighborhood, and school contexts. Journal of Educational Psychology, 100, 235-251. http://dx.doi.org/10.1037/0022-0663.100.2.235

Bales, K. (2004). Disposable people: New slavery in the global economy. Berkeley, CA: University of California Press.

Bales, K. (2005). Understanding global slavery: A reader. Berkeley, CA: University of California Press.

Bales, K. (2007). What predicts human trafficking? International Journal of Comparative and Applied Criminal Justice, 31(2), 269-279. https://doi.org/10.1080/01924036.2007.9678771

Barner, J. R., Okech, D., \& Camp, M.A. (2014). Socio-economic inequality, human trafficking, and the global slave trade. Societies, 4, 148-60.

Banks, D., \& Kyckelhahn, T. (2011). Characteristics of suspected human trafficking incidents, 2008-2010. Department of Justice, Bureau of Justice Statistics report. Retrieved from https://www.bjs.gov/content/pub/pdf/cshti0810.pdf/

Behrman, J. (1996). The impact of health and nutrition on education. World Bank Research Observer, 11(1), 23-37. https://doi.org/10.1093/wbro/11.1.23

Bernstein, E. (2018). Brokered subjects: Sex, trafficking and the politics of freedom. University of Chicago Press.

Betti, E. (2016). Precarious work: Norm or exception of capitalism? Historicizing a contemporary debate: A global gendered perspective. In E. Betti \& K. Miller (Eds), The power of the norm: Fragile rules and significant exceptions. Vienna: IWM Junior Visiting Fellows' Conferences, 35.

Boyden, J. (1994). The relationship between education and child work. UNICEF Innocenti Occasional Papers. Retrieved from https://www.unicef-irc.org/publications/pdf/crs9.pdf

Breman, J., \& Van der Linden, M. (2014). Informalizing the economy: The return of the social question at a global level. Development and Change, 45(5), 920-940.

Campbell, J. (2017). The Lord's Resistance Army persists. Council on Foreign Relations. Retrieved from https://www.cfr.org/blog/lords-resistance-army-persists

Chall, J. (2002). The academic achievement challenge: What really works in the classroom? New York: Guilford.

Cortes, F. (2018). The white savior complex. Adolescent Learners in Urban Contexts. Retrieved from https:/wp.nyu.edu/urbanyouthnyu/2018/09/10/the-white-savior-complex/

Creative Associates International. (2002). NGOs as deliverers of basic education. Bangladesh Education Sector Review. Retrieved from http://www.beps.net/publications/bangladesh\%203$\% 20$ ngos\%20as\%20deliverers\%20of\%20basic\%20education.pdf

Darby, O. (2019). Breaking language barriers empowers vulnerable women. Thomas Reuters Foundation News. Retrieved from https://news.trust.org/item/20190213175112-rsuj1

Dell, N. A., Maynard, B. R., Born, K. R., Wagner, E., Atkins, B., \& House, W. (2019). Helping 
survivors of human trafficking: A systematic review of exit and postexit interventions.

Trauma, Violence, \& Abuse, 20(2), 183-196. https://doi.org/10.1177/1524838017692553

Dennis, C. (2020). International aid's voluntourism problem. NonProfit Quarterly. Retrieved from https://nonprofitquarterly.org/international-aids-voluntourism-problem/

Department of Homeland Security. (n.d.). Blue Campaign. Retrieved from https://www.dhs.gov/blue-campaign

Dewey, J. (1934). Individual psychology and education. The Philosopher, 12. Retrieved from http://www.the-philosopher.co.uk/2016/08/individual-psychology-and-education1934.html

Ellery, V. (2019). Why education is the greatest human trafficking prevention tool. ASCD. Retrieved from https://inservice.ascd.org/why-education-is-the-greatest-humantrafficking-prevention-tool/

Ezeibe, C., Oguonu, C., Ajaero, C.K., Osadebe, N., Agbo, H. \& Uwaechia, O. (2021). From vulnerability to sustainability: Implementation of free education programmes and reversal of child trafficking in Nigeria. Journal of Human Trafficking, 7(1), 104-118. https://doi.org/10.1080/23322705.2019.1647506

Falvey, D. (2014). Is teaching English in poor countries a misguided form of philanthropy? New Internationalist. Retrieved from https://newint.org/blog/2014/07/09/teaching-englishmisguided-aid

Feingold, D. (2017). Playing the numbers: The spurious promise of global trafficking statistics. Anti-Trafficking Review, 8, 153-156. Retrieved from www.antitraffickingreview.org

Ferguson, S. (2020). Fleeing Boko Haram, and tricked into sexual exploitation. UNICEF USA. Retrieved from https://www.unicefusa.org/stories/fleeing-boko-haram-and-trickedsexual-exploitation/32525

Foshay, A. W. (1991). The curriculum matrix: Transcendence and mathematics. Journal of Curriculum and Supervision, 6(4), 277-293. Retrieved from https://eric.ed.gov/?id=EJ428441

Friedus, A. (2017). Volunteer tourism: What's wrong with it and how can it be changed? The Conversation. Retrieved from https://theconversation.com/volunteer-tourism-whatswrong-with-it-and-how-it-can-be-changed-86701

Freire, P. (1972). Pedagogy of the oppressed. Harmonsdworth UK: Penguin.

Gallagher, A. (2017). What's wrong with the Global Slavery Index?. Anti-Trafficking Review, 8, 90-112. Retrieved from www.antitraffickingreview.org

Global Slavery Index. (n.d.). Homepage. Walk Free Foundation. Retrieved from https://www.globalslaveryindex.org

Gozdziak, E. (2016). Trafficked children and youth in the United States: Reimagining survivors. Piscataway, NJ: Rutgers University Press.

Gozdziak, E. \& Bump, M. (2008). Data and research on human trafficking: Bibliography of research-based literature. Institute For the Study of International Migration. Retrieved from https://www.ojp.gov/pdffiles1/nij/grants/224392.pdf

Gozdziak, E., \& Lowell, L. (2016). After rescue: Evaluation of strategies to stabilize and integrate adult survivors of human trafficking to the United States. National Institute of Justice. Retrieved from https://www.ojp.gov/pdffiles1/nij/grants/249672.pdf 
Guarcello, L., Lyon, S., \& Valdivia, C. (2015). Evolution of the relationship between child labour and education since 2000: Evidence of 19 developing countries. UNESCO Digital Library. Retrieved from https://unesdoc.unesco.org/ark:/48223/pf0000232455

Harmon, R., Arnon, D., \& Park, B. (2020). TIP for Tat: Political bias in human trafficking reporting. British Journal of Political Science, 1-11. https://doi.org/10.1017/S0007123420000344

Haynes, J. (2019). The wastefulness of human trafficking awareness campaigns. OpenDemocracy: Beyond Trafficking and Slavery. Retrieved from https://www.opendemocracy.net/en/beyond-trafficking-and-slavery/wastefulness-ofhuman-trafficking-awareness-campaigns/

Hechenberger, E. (2019). The impact of international volunteers on education quality in developing countries: An assessment of organisations' volunteer recruitment and management practices. Iberoamerica Journal of Development Studies, 8(2), 143-170. https://doi.org/10.26754/ojs_ried/ijds.421

Huijsmans, R., \& Baker, S. (2012). Child trafficking: 'worst forms' of child labor or worst approaches to child migrants? Development and Change, 43(4), 919-46. https://doi.org/10.1111/j.1467-7660.2012.01786.x

ILO. (n.d.a). Child labour and education. Retrieved from https://www.ilo.org/ipec/Action/Education/lang--en/index.htm

ILO. (n.d.b). Formal education and the prevention of child labor. Retrieved from https://www.ilo.org/ipec/Action/Education/Formaleducationandthepreventionofchildlabo ur/lang--en/index.htm

ILO. (1973). Convention C138. Retrieved from https://www.ilo.org/dyn/normlex/en/f?p=NORMLEXPUB:12100:0::NO::P12100_ILO_C ODE:C138

Jakubiak, C. (2016) Ambiguous aims: English-language voluntourism as development. Journal of Language, Identity \& Education, 15(4), 245-258, https://doi.org/10.1080/15348458.2016.1195270

Keely, M. (2020). Officials: Parents selling own children into human trafficking. WJAC. Retrieved from https://wjactv.com/news/local/officials-parents-selling-own-children-intohuman-trafficking

King, M.L. Jr. (1947). The purpose of education. Morehouse College, [speech]. Retrieved from https://kinginstitute.stanford.edu/king-papers/documents/purpose-education

Klein, N. (2008). The shock doctrine: The rise of disaster capitalism. Picador.

Kluttz, J. (2015). Reevaluating the relationship between education and child labour using the capabilities approach: Policy and implications for inequality in Cambodia. Theory and Research in Education, 13(2), 165-179. https://doi.org/10.1177/1477878515593886

Laczko, F., \& Gozdziak, E. (2005). Data and research on human trafficking: A global survey. International Migration, 43(1/2), 5-342, Retrieved from https://publications.iom.int/system/files/pdf/global_survey.pdf

Laser-Maira, J.A, Huey, C.S., Castro, O., Ehrlich, K.H., \& Nicotera, N. (2018). Human trafficking in Peru: Stakeholder perceptions of how to combat human trafficking and help support its survivors. Journal of Sociology and Social Work, 6(1), 34-40. https://doi.org/10.15640/jssw.v6n1a5

Littrell, J. (2015). Human trafficking in America's schools. Department of Education. Retrieved 
from

https://safesupportivelearning.ed.gov/sites/default/files/HumanTraffickinginAmericasSch ools.pdf

Loh, L.C. (2019). Opinion: Volunteering abroad is popular and problematic, let's fix it. NPR. Retrieved from https://www.npr.org/sections/goatsandsoda/2019/09/12/754347433/volunteering-abroadis-popular-and-problematic-lets-fix-it

Morgan, P. L., Farkas, G., Hillemeier, M. M., \& Maczuga, S. (2009). Risk factors for learningrelated behavior problems at 24 months of age: Population-based estimates. Journal of Abnormal Child Psychology, 37, 401-413. https://doi.org/10.1007/s10802-008-9279-8

Murdock, S., Zey, M., Cline, M., \& Klineberg, S. (2010). Poverty, educational attainment and health among America's children: Current and future effects of population diversification and associated socioeconomic change. Journal of Applied Research on Children: Informing Policy for Children At Risk, 1(2), 1-33. Retrieved from https://digitalcommons.library.tmc.edu/cgi/viewcontent.cgi?article=1007\&context=childr enatrisk

Murray, C. (2020). US criticized over top anti-trafficking ranking despite failings. Thomas Reuters Foundations. Retrieved from https://www.reuters.com/article/us-usahumantrafficking-trfn/u-s-criticized-over-top-anti-trafficking-ranking-despite-failingsidUSKBN2402XE

Nagaraj, A. (2018). 500,000 trafficking to get vocational training. Mint. Retrieved from https://www.livemint.com/Politics/R3o7kSYc39GIGjO21RebYM/500000-traffickingsurvivors-to-get-vocational-training.html

No White Saviors. (2018). When white saviorism turns deadly: American missionary played Doctor, children died, when will there be justice? Nowhitesaviors.org. Retrieved from https://nowhitesaviors.org/when-white-saviorism-turns-deadly-american-missionaryplayed-doctor-children-died-when-will-there-be-justice/

Ogonor, B.O., \& Osunde, A.U. (2007). The Universal Basic Education Programme and female trafficking in South-South, Nigeria. International Journal of Lifelong Education, 26(6), 607-620. https://doi.org/10.1080/02601370701711299

OVCTTAC. (n.d.a). Education and job training/placement. Office for Victims of Crime: Training and Technical Assistance Center. Retrieved from https://www.ovcttac.gov/taskforceguide/eguide/4-supporting-victims/44-comprehensivevictim-services/education-job-trainingplacement/

OVCTTAC. (n.d.b). Overcoming language barriers. Office for Victims of Crime: Training and Technical Assistance Center. Retrieved from https://www.ovcttac.gov/taskforceguide/eguide/3-operating-a-task-force/34-addressingcommon-operational-challenges/overcoming-language-barriers/

Raphael, J. (2020). Parents as pimps: Survivor accounts of trafficking of children in the United States. Dignity: A Journal on Sexual Exploitation and Violence, 4(4), 1-34. https://doi.org/10.23860/dignity.2019.04.04.07

Rose, P. (June, 2007). NGO provision of basic education: Alternative or complementary service delivery to support access to the excluded. Create Pathways to Access. University of Sussex: Center for International Education. [research monograph].

Smith, M.K. (2021). What is education? A definition and discussion. INFED. Retrieved from https://infed.org/mobi/what-is-education-a-definition-and-discussion/ 
Spires, R., \& Tost, J. (2017). Rural Cambodian women's perspectives: An exploratory study on community ailments, migration and opportunity. Asia Pacific Journal of Social and Behavioral Sciences, 14, 9-26. Retrieved from http://research.buksu.edu.ph/index.php/APJSBS/article/view/92

Spires, R. (2015). Preventing human trafficking: Education and NGOs in Thailand. Surrey: UK. Ashgate Publishing Company.

Spires, R. (2014, July). Human trafficking NGOs in Thailand: A two-site case study of the children served in educational programs. Slavery Today, 1(2), 93-118.

Standing, G. (2009). The precariat: The new dangerous class. Bloomsbury Academic.

Surtees, R. (2013). After trafficking: Experiences and challenges in the (re)integration of trafficked persons in the greater Mekong sub-region. Bangkok: UNIAP/NEXUS Institute. Retrieved from https://nexusinstitute.net/wp-content/uploads/2015/03/aftertrafficking_experiences-and-challenges-in-reintegration-in-the-gms.pdf

Tidball, S. \& Rajaram, S.S. (2017). Schools and anti-trafficking awareness: Education/training key influences and students. University of Nebraska Medical Center. Retrieved from https://www.unmc.edu/publichealth/departments/healthpromotion/facultyandstaff/01Trafficking-Report-final.pdf

Tost, J., Spires, R., \& In, S. (2020). Cambodian youth perspectives on social and educational barriers: An exploratory case study in a rural border region. Journal of Interdisciplinary Studies in Education, 8(2), 130-146. https://doi.org/10.32674/jise.vi0.1227

UN DESA. (2020). World Social Report 2020. United Nations Department of Economic and Social Affairs-Social Inclusion. Retrieved from https://www.un.org/development/desa/dspd/world-social-report/2020-2.html

UN DESA. (2015). Transforming the world: The 2030 Agenda for Sustainable Development. United Nations Department of Economic and Social Affairs-Sustainable Development. Retrieved from https://sdgs.un.org/2030agenda

UN News. (2017). UN warns of trafficking, sexual abuse in shadow of Rohingya refugee crisis. Retrieved from https://news.un.org/en/story/2017/11/636002-un-warns-traffickingsexual-abuse-shadow-rohingya-refugee-crisis

UNODC. (2008). An introduction to human trafficking: Vulnerability, impact and action. UN.GIFT. Retrieved from https://www.unodc.org/documents/humantrafficking/An_Introduction_to_Human_Trafficking_-_Background_Paper.pdf

UNODC. (n.d.) Chapter 8: Tool 8.9- Rehabilitation, skills training and education. Toolkit to combat trafficking in persons. Retrieved from https://www.unodc.org/documents/humantrafficking/Toolkit-files/08-58296_tool_8-9.pdf

UN OHCHR. (n.d.). Recommended principles and guidelines on human rights at international borders. United Nations Office of the High Commissioner on Human Rights. Retrieved from https://www.ohchr.org/Documents/Issues/Migration/OHCHR_Recommended_Principles Guidelines.pdf

UN OHCHR. (2000). Protocol to Prevent, Suppress and Punish Trafficking in Persons Especially Women and Children, supplementing the United Nations Convention against Transnational Organized Crime. Retrieved from https://www.ohchr.org/en/professionalinterest/pages/protocoltraffickinginpersons.aspx

US Department of Education. (2017). The human trafficking framework for instructional programming in schools. Retrieved from 
https://safesupportivelearning.ed.gov/sites/default/files/USDOE_UseCase_HT_2017.pdf US Department of Health and Human Services. (2020). Human Trafficking Youth Prevention Education (HTYPE) Demonstration Program. Office on Trafficking in Persons. Retrieved from https://www.acf.hhs.gov/otip/grant-funding/htype-human-trafficking-youthprevention-education-demonstration-program

US Department of Labor. (n.d.). Working to eliminate the worst forms of child labor, forced labor and human trafficking worldwide. Retrieved from https://www.dol.gov/sites/dolgov/files/ILAB/child_labor_reports/OCFTBooklet.pdf Vo, J. (2016). Breaking the cycle: Shifting towards effective education reform to overcome poverty and abate Cambodia's sex industry. Suffolk Transnational Law Review, 39(2). 481-507. 